\title{
The effect of assessment form to the ability of student to answer the problem correctly
}

\author{
Arifian Dimas ${ }^{1}$ Cari $^{2}$, Suparmi $^{3}$, Jeffry Handhika ${ }^{4}$ \\ ${ }^{1}$ Graduate Program, University of Sebelas Maret, Surakarta, INDONESIA \\ ${ }^{2,3}$ Department of Physics, Postgraduate Program, University of Sebelas Maret, Surakarta, \\ INDONESIA
}

${ }^{4}$ IKIP PGRI Madiun,INDONESIA

Email: arifiandimas39@gmail.com

\begin{abstract}
Assessment is an important part of education. For educators, are collecting information about students learning and information about the learning process. For students, the assessment is the process of informing them about the progress of learning. Effective assessment process is responsive to the strengths, needs and clearly articulated student learning objectives. This research was aimed to know the effect of assessment form towards students ability in answering the problem correctly on kinematics and dynamics of motion. The method used in this research is descriptive qualitative. The data collecting method are assessment test and interview. Assessment test instrument are written test and animation form test. The question we use was taken "Force Concept Inventory" on kinematics and dynamics concepts. The sample are 36 student of $6^{\text {th }}$ terms student of Physics Undergraduate Departement in Sebelas Maret University. The result shows that for kinematics concept, more students answer correctly for test presented in animation form but for dynamics concept conventional test is better.
\end{abstract}

\section{Introduction}

Assessment is an important part of education. For educators, are collecting information about students' learning and information about the learning process. For students, the assessment is the process of informing them about the progress of learning. Effective assessment process is responsive to the strengths, needs and clearly articulated student learning objectives [1]. The fact that teacher should continue intuitively develope assessment is to monitor students understanding [2]. Kinematics and dynamics were one of fundamental matter in physics that studied about equation of motion [3]. Students can't solve problems because they do not understand the sentence questions, they do not understand because they think the sentence is not clear. On the other hand, students understand the sentences of the problem but they do not understand the physics concept. Contextual form of question is urgently needed because applicable with physics. The role of animation in assessment was used to make student easily understand the concept in question. Animation gave impact in student ability toward student concept learning [4]. Technology of multimedia animation can be used as tool to make clear the concept [5]. There was indication in assessment about dynamics phenomena, such as motion of a matter, would be effective if presented in animation 
form [6], [7]. There were some evidences showed that to understand phenomena of motion, student needed animation [6], [8]. This research described the finding about effect of assessment form towards the ability of student to give correct answer of kinematics and dynamics of motion. Research about the use of assessment in animation form to assess students understanding in physics has been done [9]. The assessment in form can increase the students conceptual understanding in Newton's Law. Some other researchers also investigated about kinematics about concept of vector based on content and context [10]. Research about concept of speed and velocity in visual and mathematics representation [11]. Researchers provide recommendations for investigating the visual language and mathematics that can be easily understood by students [3].

\section{Method}

The method used in this research is descriptive qualitative. The data collecting method are assessment test and interview. Assessment test instrument are written test and animation form test. The Question we use was taken Force Concept Inventory (FCI) on kinematics and dynamics concepts [12]. The sample are 36 Student of $6^{\text {th }}$ terms students of Physics Undergraduate Department in Sebelas Maret University.

\section{Result and Discussion}

The percentage of correct answer of physics student in doing test of conventional test (written test) and animation form test of kinematics and dynamics concepts is presented in Table 1.

Table 1. Result of Assessment

\begin{tabular}{|c|c|c|c|}
\hline \multicolumn{4}{|c|}{ Correct Answer (\%) } \\
\hline Problem & $\begin{array}{l}\text { Number of } \\
\text { Items }\end{array}$ & $\begin{array}{c}\text { Problem presented in } \\
\text { sentences }\end{array}$ & $\begin{array}{l}\text { Problem presented in } \\
\text { the simulation }\end{array}$ \\
\hline Kinematics & 1 & $42 \%$ & $47 \%$ \\
\hline Kinematics & 7 & $31 \%$ & $43 \%$ \\
\hline Kinematics & 8 & $19 \%$ & $31 \%$ \\
\hline Kinematics & 3 & $17 \%$ & $42 \%$ \\
\hline Newton Law's I & 2 & $14 \%$ & $11 \%$ \\
\hline Newton Law's III & 5 & $17 \%$ & $11 \%$ \\
\hline Newton Law's III & 6 & $3 \%$ & $0 \%$ \\
\hline
\end{tabular}

Based on table 1, it is shows that there are differences of student answer between seven written test and animation tests. In four questions of kinematics, animation form gives better result and the other three questions Newton Law's gives better result on written test form. Percentage of average score of conceptual understanding shows that the use of animation assessment is better than percentage of average score of written test assessment. 
From 7 questions, some information can be obtained by students answer, such as animation is a problem type that directs the students to answer correctly. By the animation, the error probability in answering written test problem type can be reducible. However, another animation problems make students answer became wrong. Student result answer of kinematics in animation form is better than written test form. But in dynamics of motion, written test form is better. In kinematics, question relates to motion without notice the cause so students more understand the problem of motion on animation. While in dynamics of motion questions notice the cause of motion. Because forces in animation question can't well described (abstract), students can't understand the problem. It is shown comes from separated interview with the students. The difference between two type of test is not indicate the one which is better in problem type, it needs to take the deep investigaton to make a decision. It is clear enough that animation form test type can make a difference result in some certain condition. The example of kinematics problem about motion it shown on Figure 1.
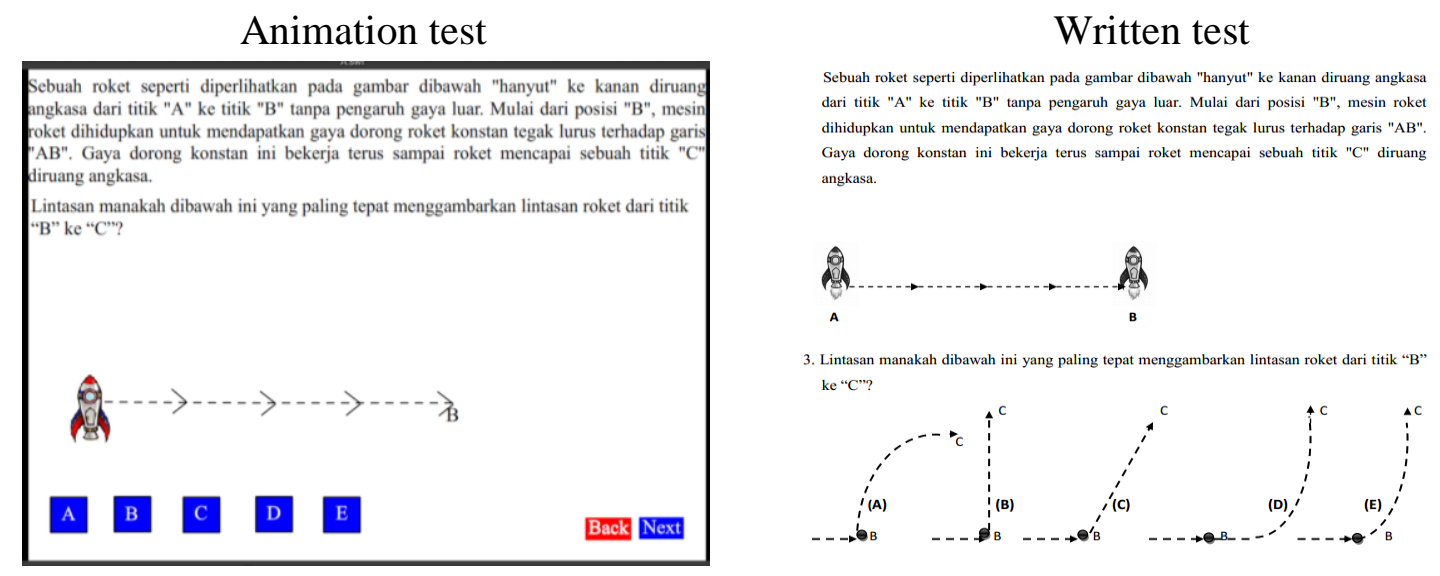

Figure 1. Assessment test number 3

\section{Interview result:}

\subsection{Understanding written test needed more of concentration than animation test}

In resolving this issue, from a few students showed answer is false when they do written test because their less concentration. On the matter of animation they do not need to imagine about the questions presented. Interview with Govinda," Animation is easiest because it show me the motion but written test makes me just imagined. I must move my hand to figure what about the motion but animation test does not need that". Written test just showing senteces to describe about movement then it makes student need to much concentration to understand the test.

\subsection{Students did not understand written test}

In some students can not understand the question because the sentence is confusing. This case makes the student confused when they choose the answer. It showed from Rio Rizky statement, “I work this test by using logically thinking without understanding the 
concept, I just imagined." . From this interview, the student is less in understanding this concept then, he answered the test by imagined.

\subsection{Animation test reduce the missunderstanding of sentences animation test}

Animation test makes the question easy because it served the question by motion. Due to the motion on the matter of animation students do not need to imagine intent questions presented. The interview result with Nilam, "Written test is difficult to understand. I am easy to understand when this test served by animation test because it completed with ilustration." Animation is also quicked the university student understanding in order to understand the test. The result of movement concept understanding increased than written test [9].

\section{Animation test}

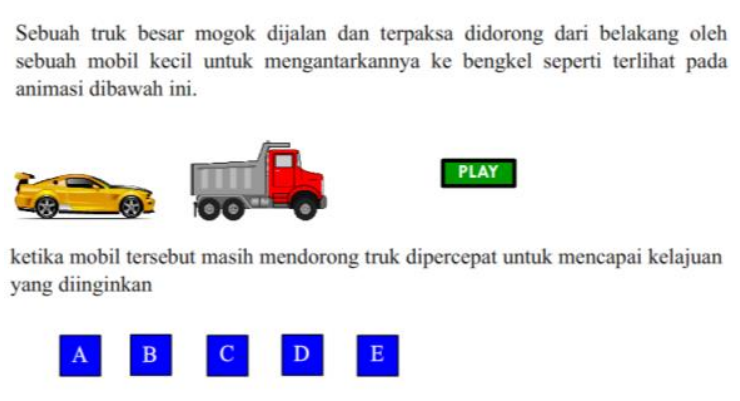

Back Next
Written test

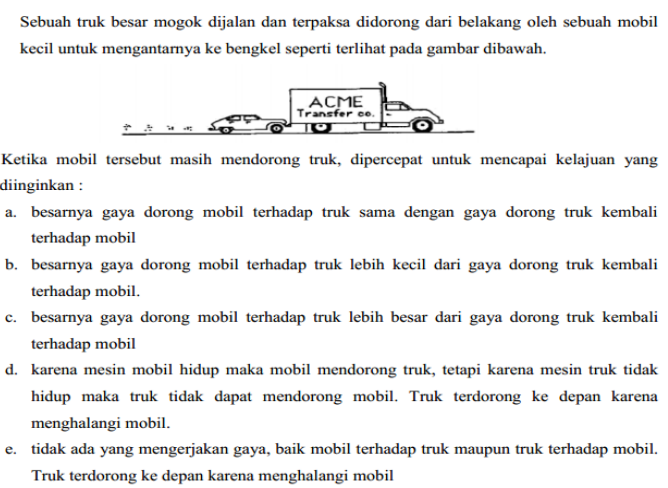

Figure 2. Assessment test number 6.

\subsection{Animation makes the student 's answer false}

From some questions animations make the student answers incorrectly. For example in Figure 2, test about truck that push a car then they work together, the test ask about the energy if truck and a car. The result of student interview, " The car should push the truck using more enery in order to make the truck reached the auto repair shop". The student assumed that the car push the truck and energy of the car bigger than the truck. This causes the student answers incorrectly.

\section{Conclusion}

Based on interview and data analysis, The result shows that for kinematics concept, more students answer correctly for test presented in animation form but for dynamics concept conventional test is better. In kinematics, question relates to motion without notice the cause so students more understand the problem of motion on animation. While in dynamics of motion questions notice the cause of motion. Because forces in animation question can't well described (abstract), students can't understand the problem.

\section{References}

[1] Goode K, Kingston T, Grant M J, and Munson L 2010 Etfovoice. 21 
[2] Griffin P 1991 Educational Assesment and Reporting. Sydney (Harcourt Brace Jovanovic) p 3-4

[3] Handhika J, Cari, Soeparmi and Sunarno W 2015 Procedings of international Seminar on Mathematics, Science, and Computer Science Education (MSCEIS).1708 070005

[4] Su K D and Yeh S C 2014 The Turkish Online Journal of Educational Technology (TOJET). 1388

[5] Lee W W and Owens D L 2004 Multimedia-Based Instructinal Design (San Francisco, USA: Pfeiffer, an imprint of Wiley)

[6] Rieber L 1994 Computers, Graphics, and Learning (USA) p 66

[7] Beichner R 1996 Am.J.Phys. 641271

[8] Meyer R E and Anderson R B 1992 Journal of Educational Psychology. 84444

[9] Dancy M H 2006 Physics Education Research. 2010104

[10] Barniol P and Zavala G 2014 Physical Review Special Topics-Physcs Education Research.10 020115

[11] Rich R. M 2014 International journal of STEM education. Springer. 1-7

[12] Hestenes D Wells M dan Swackhamer G. 1992. The Physics Teacher. 30 141-151 